\title{
Education for optics as a service technology
}

\section{William Swift}

D. William Swift, "Education for optics as a service technology," Proc. SPIE 3190, Fifth International Topical Meeting on Education and Training in Optics, (8 December 1997); doi: 10.1117/12.294374

Event: Fifth International Topical Meeting on Education and Training in Optics, 1997, Delft, Netherlands 


\title{
Education for optics as a service technology
}

\author{
D. William Swift \\ Swift Technical Services, Prestatyn, LL19 9PB, Wales
}

\begin{abstract}
Optics for industry today is a branch of engineering; at this level the science is well understood and what is required is the ability to use it to make devices and systems for application. The optical and electro-optical companies which specialise in this area are able to educate and train their own employees satisfactorily as a consequence of their extensive experience, even if their new recruits are inadequately informed when they join; but in fact many of them come from universities with strong optical departments and so are very well informed. However, because optics is today so widely used throughout industry, for everything from alignment, communications and data storage to security and viewing, it is becoming a service technology and many non-specialist engineers now need to use and understand optical and electro-optical systems. This presents new challenges, and this paper will consider how they might be met.

Keywords: Education. Engineering. Industry. Optics. Service technology.
\end{abstract}

\section{INTRODUCTION}

Education in applied optics in the form needed by industry is well supplied by many, though not all, universities. The more recent parts of optics, such as integrated optics or diffractive optics, and particular specialisations, such as lens design or illumination, are well covered in most specialist university optical departments. Such departments are not present in all universities, but there are sufficient good ones to satisfy the need currently; at least, that is true in the U.K. and in those countries in continental Europe of which I have any direct experience. That does not mean, of course, that graduates necessarily fit their jobs very closely when first appointed, because the needs of different companies vary widely and it would be unrealistic to expect that they could all be covered; nor does it mean that the fit will remain adequate, however good it may be initially, because companies' needs change over time and technology progresses. Therefore it is essential that any good optical engineer keeps abreast of developments and learns as he or she goes along, both on the job and from internal or external courses and from technical conferences.

\section{THE PRESENT SITUATION}

Optics as practised in industry today is a branch of engineering rather than a science, because the science needed to understand it well enough to use it for designing and building systems is well understood; and it is fast becoming a service technology, similar to electronics, used for widespread applications such as alignment, communications, data storage, displays, imaging, inspection, measurement, ophthalmics, security, sensors, testing, viewing - and many other things, including activeapplications such as laser machining and laser surgery. In consequence many engineers, whatever their basic discipline, will need to use and understand optical devices or systems at some time in their career The people who design these systems will be specialists and probably most of the readers of this paper are in that category, but my concern here is not with them but with the non-specialist engineer or user. As an example, take someone who has to install a system for measuring some aspect or aspects of products passing on a production line. An electro-optical system is almost certain to be one possibility of several that are worth considering. The actual choice is likely to depend largely on the the previous experience of the person responsible, and if optics is to be correctly assessed this person should know something about it. Ideally all engineers should be taught at least basic optics, if only to ensure that they understand when optical technology should be considered as appropriate for any given application, and what advantages and disadvantages it has. Optics should be a part of every engineer's education. 


\section{SUGGESTED APPROACH}

That may be the ideal, but it is not practicable because most engineering courses are already heavily loaded or even overloaded. What can be done about this problem? It is unlikely that significant extra time, or significant extra money, can be made available in the present economic climate; existing courses are losing resources and not gaining them. However, I would like to suggest that it might be possible to find enough time to present a couple of lectures giving typical examples of applications just to provide a very basic introduction, so that people might be alerted to the possibilities. This would be very much a second-best approach but it would not take up much time, it would not cost much, and it would be significantly better than nothing.

Which students should be targetted? Electronic engineers and mechanical engineers certainly, and of course applied physicists, many of whom become engineers. This last group is particularly interesting. Those universities with strong optics departments often produce graduates who are very knowledgeable about optics generally, but some universities without such departments seem to regard it as a narrow speciality in which they need have no interest, and that, I suggest, is unacceptable.

Who should present the lectures? Many university departments probably have at least one staff member with sufficient knowledge to do it well, but not all; and even where they have it is unlikely that the staff member will have recent experience in industry and therefore that they will have appropriate practical know-how. It seems to me that this is a serious shortcoming. It was what made me decide to spend some time in industry before entering a university career and in the end I never did do so full-time. I suggest that the optimum way out of this problem is a visiting industrial lecturer. Providing that the right person is chosen this has all the advantages without any serious disadvantages; it is even inexpensive. It has in particular the important function of helping to bridge the gap between academic optics and industrial optics which still exists to a very significant extent.

\section{PROBLEM AREAS}

Are there any particular problems in putting these suggestions into practice? Unfortunately, yes. First and foremost is the fact that, as remarked earlier, practically all technology courses are already heavily loaded. Clearly this cannot be ignored, but there is a real need for a minimal amount of applied optics nonetheless and it should receive proper consideration. There is also at least one significant further point, which is the fact that optics is widely seen as having been around for a long time and being "old-fashioned". It has been around a long time, but it is most certainly not old fashioned. In communications, for example, optical fibre transmission is a good example of optics carrying more information, faster, with less interference for, and less interference from, surrounding systems than electronics, and in the not too distant future we may see the computer going optical as well. So this objection has no foundation in fact at all, but it seems to be supported by an irrational "gut-feeling" which possibly stems largely from ignorance about the extent of the subject today. Fortunately not everyone shares this particular misinformed view; but it is widespread and needs to be combatted by those of us with inside knowledge.

\section{CONCLUSION}

So what am I suggesting? Two things: an improved presentation of optics as the service technology of the future, not replacing electronics but taking over some of its more hi-tech applications, and some minor exposure to optical methods and applications for mechanical engineering students, electronic engineering students, and those applied physics students who currently do not receive it, probably by means of occasional guest lectures from industrial optical engineers. Some exposure is probably all that is needed since optics is naturally fascinating and once introduced to it and its possibilities most intelligent people will want to teach themselves more anyhow. 